\title{
A educação física e concepções higienistas sobre raça: uma rein- terpretação histórica da educação física brasileira dos anos de 1930
}

\author{
Edivaldo Góis Junior ${ }^{1}$ \\ Hugo R. Lovisolo ${ }^{2}$ \\ https://doi.org/10.5628/rpcd.05.03.322
}

\author{
${ }^{1}$ Universidade Cidade de São Paulo \\ São Paulo \\ 2 Universidade Gama Filho \\ Rio de Janeiro \\ Brasil
}

\begin{abstract}
RESUMO
Este estudo pretende averiguar se as correntes teóricas do "movimento higienista", determinadas pelas ciências biológicas, influenciavam as discussões sobre Educação Física no Brasil dos anos de 1930. A partir da hipótese de reprodução das concepções higienistas por parte da área de Educação Física, foi necessário investigar os periódicos especializados da época, como a Revista Educação Physica (1932-1945) e a Revista de Educação Física do Exército (1932-2000), que compõem o conjunto de fontes primárias. Analisou-se os conteúdos das fontes primárias e, finalmente, verificou-se a sustentação da hipótese. Em conclusão, houve uma reprodução das concepções higienistas, como a corrente lamarkista e galtoniana, no campo da educação física brasileira nos anos de 1930.
\end{abstract}

Palavras-chave: educação física, história, higienistas.

\begin{abstract}
Physical Education and hygienist conceptions about race: A history of Brazilian Physical Education in the 1930's.

This study aims to verify if the hygienists' theories were reproduced by the Brazilian Physical Education thought in the 1930's. This view was accomplished through an historical research comparing major sources (specialized journals), as "Revista Educação Physica" (1932-1945) and "Revista de Educação Física do Exército" (1932-2000). The interpretations of the historical studies of the Physical Education in Brazil supported our first view of the problem. In conclusion, there was a reproduction of the hygienists' theories, as the Lamarck's and Galton's ideas, in the Brazilian Physical Education in the 1930's.
\end{abstract}

Key Words: physical education, history, hygienists. 


\section{INTRODUÇÃO'}

Nas últimas décadas do século XIX, no Brasil, surgia um novo pensamento por parte dos profissionais da área da saúde. Suas propostas residiam na defesa da Saúde Pública na educação e no ensino de novos hábitos higiênicos. Convencionou-se chamá-lo de "movimento higienista". O movimento tinha uma idéia central: a de valorizar a população como um bem, como capital, como recurso, talvez principal, da Nação (1, 2, 3). A valorização continuou presente no século XX e diversas concepções higienistas surgiram na Europa, sobretudo na França e Inglaterra, como as tendências lamarckista e galtoniana. O movimento higienista de origem européia, produto da crescente industrialização na Inglaterra, França e Alemanha, chegou, definitivamente, ao Brasil no início do século $\mathrm{XX}$, à medida que o país tentava consolidar um projeto de modernização que tinha como modelo a Europa. No Brasil foi objeto de reapropriações e reinterpretações, geralmente baseadas na famosa idéia positivista de adequação, basicamente preconizando normas, hábitos, que colaborariam com o aprimoramento da saúde coletiva, do povo, da raça $(4,5,6)$.

Este estudo pretende mostrar que as correntes teóricas do "movimento higienista", determinadas pela áreas de medicina e biologia, influenciavam as discussões sobre educação física no Brasil. O problema central do estudo consiste em entender as relações entre as concepções higienistas e os modos de intervenção da educação física no Brasil. Parte-se da hipótese de que a educação física, um campo profissional ainda novo nas primeiras décadas do século XX e que enfrentava problemas de identidade e legitimidade, se apropriou de forma reprodutiva, teórica e tecnicamente, das contribuições do movimento higienista. A hipótese será trabalhada no conte xto das fontes primárias da educação física brasileira nos anos de 1930.

Em outros textos mostramos a continuidade do movimento higienista $(7,8,9)$. Neste, pretendemos enfatizar a dependência da educação física em relação à medicina e à biologia no tempo de sua institucionalização enquanto campo profissional. Contudo, desejamos postular que essa dependência talvez ainda não tenha acabado no campo das relações específicas entre atividade física e saúde.
Na busca de resposta para a questão, a partir da hipótese de reprodução das concepções higienistas por parte da área de educação física, investigámos os periódicos especializados da época, como a Revista Educação Physica (10) e a Revista de Educação Física do Exército (11), entendidos como o conjunto de fontes primárias. Analisaram-se os conteúdos das fontes primárias e, finalmente, verificou-se a sustentação da hipótese de reprodução das concepções higienistas no campo da educação física brasileira nos anos de 1930 .

\section{SOBRE O "MOVIMENTO HIGIENISTA" NO BRASIL}

$\mathrm{O}$ "movimento higienista" na Europa teve como objetivo central a proteção da população. Os higienistas mediavam, gerando "soluções científicas", nos conflitos entre o capital e os trabalhadores, procurando desenvolver a saúde da população trabalhadora, a resistência do trabalhador, e melhores condições de trabalho no horizonte do aumento da produtividade ou acumulação das empresas (1). No Brasil o movimento teve papel semelhante no início da industrialização. Porém, havia um aspecto especialmente preocupante para os higienistas brasileiros, como Oswaldo Cruz, Belisário Penna, Miguel Couto, qual seja, a formação do povo envolvendo o papel das raças e sua miscigenação, daí decorrendo a presença de tendências eugênicas no movimento, que tinham como preocupação a higiene da raça, utilizada como sinônimo de eugenia no Brasil (4).

No início do século XX a sociedade brasileira crescia em comple xidade e diversificação, dando lugar à emergência de novos setores e atores sociais, quais sejam o desenvolvimento da ciência médica, a influência crescente do positivismo, o surgimento dos movimentos sociais de esquerda, como o anarquismo e o comunismo. Alguns políticos e intelectuais do início do século, como Alberto Torres, Oliveira Vianna, Monteiro Lobato, Gilberto Freyre, Fernando de Azevedo, Manoel Bonfim, postularam como tarefa pensar os problemas do Brasil. O que mais interessava a estes intelectuais brasileiros era conceber o porquê da falta de desenvolvimento econômico em um país imenso e berço de inúmeras riquezas naturais, tema trabalhado por Sérgio Micelli, Boris Fausto e, principalmente, por Dante Moreira Leite $(12,13,14)$. A sociedade do início de século reclama a modernização do Brasil e de suas 
cidades. Incomodava aos brasileiros o paradoxo do atraso econômico e social, sob o pano de fundo da riqueza natural. Assim, a explicação do fracasso econômico de um país, com amplas condições de ocupar um lugar entre as nações mais prósperas, passou a formar parte do debate político e intelectual (15). Mas, quando obser vavam o jovem país da América do Norte, se perguntavam o porquê de nosso fraco desenvolvimento, em comparação aos Estados Unidos e até em relação com a Argentina do início do século XX $(16,17,18)$.

Durante os anos de 1900-1920 a tese de maior repercussão para o fracasso econômico foi a fatalista, na qual os componentes explicativos raciais eram fortes. Segundo esse pensamento, os brasileiros estavam constituídos por raças inferiores, com baixa capacidade para o trabalho. Portanto, o Brasil nunca poderia ser uma nação economicamente forte. À pergunta de Von Martius, sobre se a miscigenação era boa ou ruim para o Brasil, respondia-se negativamente. Com o intuito de melhorar sua imagem, as elites brasileiras tentaram "embranquecer " o país (19). Como acreditavam que o negro e o índio eram inferiores, os brasileiros sentiam-se em desvantagem. Correntes do "movimento higienista", como a liderada por Oliveira Vianna, pensaram em estratégias de embranquecimento, como a esterilização dos negros, regulamentação de casamentos, uma crescente imigração européia, sobretudo da Itália e Alemanha (20).

Porém, uma outra corrente do movimento higienista criticaria, substancialmente, o pensamento fatalista $(21,22)$. Era o pensamento inter vencionista. Este defendia que o povo brasileiro não era produtivo, porque estava abandonado pelas autoridades governamentais, que pouco faziam pela educação e saúde dos brasileiros. O povo estava doente e abandonado $(23,24,25)$. Diferentemente dos fatalistas, os intervencionistas, entre eles Belisário Penna, Miguel Couto, exigiam do Estado uma atitude construtiva na melhoria das condições de vida da população. Os higienistas tiveram um papel preponderante para que se pensasse, e ainda pensamos, a produtividade, mais como resultado das condições dos trabalhadores, do que como produto de suas características raciais. Assim, as condições sociais, econômicas e educacionais foram mais significativas que os deter- minantes raciológicos. Provocaram, portanto, uma mudança na consciência nacional sobre os problemas brasileiros $(26,27)$.

\section{A REPRODUÇÃO DOS DEBATES RACIAIS NA EDUCAÇÃO FÍSICA BRASILEIRA}

A questão da colaboração da educação física no aprimoramento racial da população inseria-se no embate de duas orientações nos anos de 1930: uma lamarkista, de cunho inter vencionista no campo da educação, defendida por Fernando de Azevedo e outra galtonia$n a$, identificada com teorias racistas, pregando a regulamentação de casamentos e esterilização de doentes, defendida pelo professor de higiene da Escola Nacional de Educação Física da Universidade do Brasil, Waldemar Areno. As duas correntes reproduziam as contradições entre inter venção governamental no campo da educação e a determinação genética inferior do brasileiro. A teoria lamarkista, postulando a herança dos caracteres adquiridos, favorecia a inter venção, mesmo quando a ênfase fosse colocada nas condições de vida da população como fator determinante. A teoria galtoniana tinha como base, ou referência, a teoria darwiniana sobre a não transmissão dos caracteres adquiridos.

Entretanto, advogava a favor de uma política eugênica ativa no controle e planejamento da reprodução. Fernando de Azevedo, um defensor da inter venção no campo da saúde, quando é entrevistado pela Revista Educação Physica, onde foi considerado pelos redatores um apóstolo da área no Brasil, é definitivo sobre as questões deterministas raciais. O entrevistador perguntou a ele se acreditava na tão falada inferioridade física de nosso povo, ou julgava que a pobreza orgânica de nosso mestiço era produto de fatores sociais, como falta de alimentação e educação. Fernando de Azevedo respondeu desta forma:

"Existe sem duvida uma inferioridade physica, que se prende, porém, não á raça ou melhor, ás raças que entraram na composição de nosso povo, mas ás condições de vida de nossas populações rurais, sertanejas, ou praieiras. A inferioridade physica do nosso povo não é uma questão racial, mas um problema social e econômico, de saúde publica e de educação. A solução desse problema está numa política de engenharia sanitária ou de saneamento das regiões em que vegetam e se arruinam as nossas populações. (...) 
Melhoram-se as condições de vida de um povo, e o estado de saúde melhorará, em conseqüência" (28, p. 46).

A inter venção de Azevedo era pautada na democratização da educação e da saúde. Através da reforma social o povo iria superar sua debilidade, adquirindo condições de trabalho, hábitos higiênicos. Este projeto regeneraria o povo brasileiro, como aludia Azevedo. Para ele, como já mostrámos, a superioridade étnica de um povo era resultante de sua história e de sua formação genética. Sendo que o primeiro influenciaria o segundo, formando a raça (lamarkismo). Azevedo acreditava que a raça brasileira ainda estava sendo definida. Portanto, se o povo tivesse melhores condições de vida, adquirisse hábitos saudáveis, estas características adquiridas poderiam ser transmitidas geneticamente a gerações posteriores. A educação física, em seu projeto pedagógico, seguia estes princípios lamarkistas, como comprovamos abaixo:

"Uma vez introduzida pela educação nos habitos do paiz, a pratica desta cultura physica sustentada durante uma larga serie de gerações, depuraria a nossa raça de diatheses morbidas, locupletando-a, progressivamente, pela creação incessante de individuos robustos. Os mortos governam os vivos. As gerações de amanhã apuradas, por systema, pela educação physica - afinadora da raça e collaboradora do progresso - imprimiriam assim, nas que lhes succedessem, o cunho de seu caracter, para que pudessem, com o augmento do patrimonio biologico hereditario, aperfeiçoar ainda mais a natureza humana" (29, p. 14).

Com este referencial podemos perceber que a educação física, no pensamento de Fernando de Azevedo, fazia parte de um projeto de inculcação de novos hábitos, que por sua vez construiriam um novo homem brasileiro $(30,31)$. Sendo este apto ao trabalho, saudável, disposto, colaborador no desenvolvimento de uma grande nação.

A importância da educação física, em seu projeto pedagógico, é patente nas posições de Azevedo que a junta com a higiene na inter venção. Segundo ele, a educação popular, para desenvolver o país economicamente, teria que começar pela proteção higiênica e formação física da população escolar. No seu pensamento, o problema da saúde era capital em toda e qualquer organização educativa, onde a ginástica seria obrigatória e praticada em ambientes destinados para este fim, e regrados, ambiente e prática, pelas normas higiênicas. Assim sendo, a escola tradicional não poderia servir a este fim, devido às antigas instalações e à valorização do ensino intelectual. Mas este não era a único problema. Também era necessário criar os cursos de formação de professores da área. Onde eles pudessem aprender os métodos científicos para realizar a inter venção. Sem dúvida, a opinião deste educador foi determinante para a estruturação, ainda insípida e precária em sua época, da educação física (32). Ele foi um precursor da escolarização da ginástica no Brasil.

Seu projeto era o da democratização da educação e saúde. Para isto o seu melhor instrumento pedagógico era a educação física. Mas nem por este motivo foram lhe poupadas críticas por parte dos professores galtonianos. Como podemos destacar com Waldemar Areno, professor catedrático de higiene aplicada, fisiologia e anatomia da Escola Nacional. Areno discorda de Azevedo na questão do lamarckismo. Para ele, caracteres adquiridos, como valores educativos, robustez, não eram transmitidos geneticamente (33). Mas nem por isso a educação física perde o sentido em sua proposta. Porém, ele lhe atribui outro papel, não menos importante do que na proposta de Azevedo, que consistia na integração do físico e do intelectual ou psicológico, na formação do homem integral.

Para Areno, na sua época, os interesses econômicos em certas profissões impediam a aplicação dos princípios higiênicos, com o conseqüente sacrifício para a saúde. O erro, dizia ele, era flagrante, porque a recompensa do trabalho excessivo, convertida em benefício econômico, era insignificante, diante da riqueza imensa que representaria o bem viver. $\mathrm{O}$ corpo e o espírito teriam o direito aos mesmos cuidados, e a conser vação da saúde seria, verdadeiramente, um dever. Qual seria realmente o valor de um indivíduo, intelectualmente rico, que se apresentasse incapaz no físico, enfraquecido no seu vigor e na base fundamental que é a saúde? Por isto, ele afirmava que a educação física tinha muita importância, pois era um hábito higiênico capaz de aprimorar e conser var a saúde coletiva e individual. O exercício físico orientado e praticado sob as suas variadas 
modalidades, adaptado às várias idades, ao sexo, ocupação e condições individuais, proporcionaria acentuada melhoria na circulação e respiração, melhoraria as trocas metabólicas e aumentaria a atividade do sistema nervoso, por causa da melhor irrigação. Já o sedentário, na sua opinião, apresentaria uma diminuição geral da força muscular e um menor desenvolvimento dos músculos. Ainda teria diminuída a sua capacidade de trabalho intelectual e, em resumo, seria um doente, um inferior, vencido por si próprio, alegando as mais variadas enfermidades. Porém, portador realmente de um único mal responsável: a falta de exercício físico. Daí a importância da educação física para Areno. Contudo ele dizia:

“A educação física é elemento indissociável da educação, é uma das partes dela e a educação não se transmite por herança. Os filhos dos ginastas ou desportistas não usufruirão qualquer vantagem genética, em virtude do passado dos pais. Não há assim ação sôbre as células germinadoras dos efeitos dos exercícios físicos sôbre o organismo humano, efeitos que só alcançarão as células corporais, as células somáticas. E não se deve portanto repetir a afirmativa errônea, de que a educação física se destina a melhorar a raça” (34. p. 32).

Se não era a educação física que melhoraria a raça brasileira, o que seria? Na sua opinião seria a eugenia nos termos de Galton, ou seja, através da regulamentação de casamentos e da esterilização. Com isto ocorreria?

Areno defendia a existência de uma legislação que regulamentasse o casamento. Os casais passariam por um exame pré-nupcial, que diagnosticaria se aqueles indivíduos eram "disgênicos". Se não fossem, seria emitida uma autorização governamental para o casamento. Outra medida seria a esterilização dos indivíduos "disgênicos". Estes eram os doentes mentais, criminosos, tarados, nos termos dos galtonianos. Com isto o patrimônio hereditário seria conservado e aprimorado. A raça melhoraria. Como alude Reinaldo Busch:

"O Homem como rei da natureza, faz uso de sua inteligência conseguindo, pelo cruzamento experimental e seleção de genitores entre animais domésticos, produtos de bela perfeição física e de apuradas capacidades inatas. Os exímios cavalos de corrida, as vacas ricamente leiteiras, os porcos de rápida e rendosa engorda, os cães de faro ultra sensível e possuidores em alto grau de tendências específicas para diversos tipos de caças, são exemplares raciais obtidos através de pacientes investigações em que o homem interesseiramente gasta sua inteligência em observar, experimentar e raciocina para aperfeiçoar esses animais. (...)

Entretanto, sem descrer da hereditariedade de caracteres bons ou maus de robustez ou de fraquezas orgânicas na sua espécie, o homem não faz uso em si mesmo da ciência que aplica para selecionar animais. Esquece que traria reais benefícios para sua descendência se assumisse uma atitude eugênica quando tivesse de contrair núpcias. Ao invés de controlar suas impressões e sentimentos afetivos por raciocínios, em face de observações e investigações mórbidas na pessoa e na ascendência de quem é objeto de suas inclinações, ele deixa-se levar só pelo coração, ou usa o cérebro para previsões estranhas aos interesses da saúde da prole. Do ponto de vista eugênico, casa-se às vezes bem, por acaso, outras vezes mal, conhecendo ou não as predisposições hereditárias do outro cônjuge" ( 35, p. 58).

Os galtonianos defendiam a tese de que a seleção natural de Darwin deveria ser auxiliada através da inter venção do homem. Seus métodos nunca foram seguidos no Brasil. Mas, sem dúvida, tiveram influência na mentalidade da educação física, representada por periódicos da época, como a Revista Educação Physica (1932-1945) e a Revista de Educação Física do Exército (1932-2000), os dois periódicos específicos da área de educação física, publicados nos anos de 1930. O primeiro periódico publicou o artigo "Higiene e Saúde" (34) e "Como evitar a prole doentia" (35) e o segundo, em seu editorial, defendeu a eugenia e o estabelecimento de leis como a regulamentação do casamento e esterilização de doentes (36), enfim, todos artigos apresentando os pressupostos de eugenia da raça em uma vertente galtoniana. Também é interessante constatar que não encontramos nestas revistas nenhuma referência direta a uma suposta inferioridade dos negros e índios, como encontramos na bibliografia brasileira anterior aos anos vinte, como em "Raça e Assimilação" de Oliveira Vianna (22), e ainda "Clima e Saúde" de Afrânio Peixoto (21) . Como estes periódicos se organizam a partir dos anos trinta, divulgavam as teorias mais modernas, que já não falavam de uma culpa da raça 
negra e indígena em nossa debilidade física. Embora os indícios mostrem que a mentalidade higienista optou pela proposta de inter venção social, e não por uma proposta racista, pois, afinal, não adotou a orientações galtonianas de regulamentação dos casamentos, esterilização de doentes, mas sim a democratização da educação e saúde, defendida nos anos de 1930 por Fernando de Azevedo. A educação física, entre os higienistas lamarkistas e os higienistas galtonianos, não se decidiu nem por uma, nem por outra. Podemos constatar isto nos periódicos da época, na Revista Educação Physica (10) e na Revista de Educação Física do Exército (11), pois estes divulgam as duas teorias como em um debate democrático. E, além de que as duas correntes atestavam a importância da educação física. E, era isto que interessava à nossa área, como vislumbraremos em seguida.

\section{CONSIDERAÇÕES FINAIS.}

\section{AFINAL, QUAL A INFLUÊNCIA DOS HIGIENISTAS?}

A mentalidade da educação física é muito influenciada pelos ideais higienistas. Isto é claro. Diríamos, até, que é a grande influência da educação física. Embora a área da educação física ficasse exposta aos diferenciados fundamentos do "movimento higienista”, o consenso aparecia no campo da inter venção, pois tantos os galtonianos como os lamarkistas objetivavam o mesmo ideal, ou seja, o aprimoramento da saúde coletiva e individual. Contudo estabeleciam estratégias diferenciadas: enquanto os primeiros propunham a regulamentação de casamentos, esterilização de doentes para selecionar a raça brasileira e, assim, aprimorá-la $(21,22,33,34,35,36)$, tendo a educação física como instrumento de formação do homem integral, os segundos almejavam a democratização da saúde e da educação; e, para isto, contavam com a prática da educação física, acessível a todos, com o intuito de formação de uma geração forte, que daria origem a sucessivas gerações fortes, através da transmissão de genes adquiridos (28, 30, 32).

Havia também outro elemento de peso: a necessidade de legitimação.

O pensamento da área compactuou com várias concepções antagônicas, como a lamarckista e a galtoniana, que, porém, convergiam na valorização da inter venção da educação física, especialmente no campo escolar. Nos anos 30, o que importava era provar que a educação física tinha grande utilidade para a sociedade. O consenso sobre a inter venção sobrepujava as diferenças teóricas, construindo um pensamento legitimador a favor da prática.

A hipótese de reprodução das concepções higienistas, como as correntes lamarkista e galtoniana, no campo da educação física brasileira nos anos de 1930, se sustenta. Contudo, seu significado é reduzido quando nos situamos no ponto de vista da intervenção e de sua legitimação social e institucional. As diferenças teóricas não afetaram o consenso político, a consideração da educação física como política valiosa, aliada da política de saúde, na formação de um povo forte e sadio, produtivo e íntegro.

\section{NOTAS}

${ }^{1}$ A ortografia de época nas fontes primárias foi mantida.

\section{CORRESPONDÊNCIA}

\section{Edivaldo Góis Junior}

R. Aldino, 125. Vila Formosa.

03377-040 São Paulo/SP

Brasil

egoisjr@terra.com.br 


\section{REFERÊNCIAS BIBLIOGRÁFICAS}

1. Rabinbach A. (1992). The Human Motor. Los Angeles: University of California Press.

2. Rosen G. (1980) Da polícia médica à medicina social. Rio de Janeiro: Graal.

3. Rosen G. (1994). Uma história da saúde pública. São Paulo: Editora UNESP.

4. Góis Junior E. (2000) Os higienistas e a Educação Física: a história dos seus ideais. Rio de Janeiro: Universidade Gama Filho.

5. Soares CL. (1990). O pensamento médico higienista e a Educação Física no Brasil: (1850-1930). São Paulo, Pontifícia Universidade Católica.

6. Soares CL. (2001). Educação Física, Raízes Européias e Brasil. Campinas: Autores Associados, 2 ed.

7. Góis Junior E, Lovisolo HR. (2003). Descontinuidades e continuidades do Movimento Higienista no Brasil do século XX. Revista Brasileira de Ciências do Esporte 25 (1): 41-54.

8. Góis Junior E. (2003). O Século da Higiene: uma história de intelectuais da saúde. (Brasil, século $X X$ ). Rio de Janeiro: Universidade Gama Filho.

9. Lovisolo HR. (2000). História Oficial e História Crítica: pela autonomia do campo. Revista Motus Corporis 7 (2): 127-146.

10. Revista Educação Physica (1932-1945). Rio de Janeiro, Companhia Editora Nacional.

11. Revista de Educação Física do Exército (1932-2000). Rio de Janeiro, Escola de Educação Física do Exército.

12. Fausto B. (2002). História concisa do Brasil. São Paulo: Editora da USP.

13. Leite DM. (1976). Caráter Nacional Brasileiro. São Paulo: Pioneira, 3ed.

14. Micelli S. (2001). Intelectuais à brasileira. São Paulo: Companhia das Letras.

15. Nagle J. (1974). Educação e Sociedade na Primeira República. São Paulo: Editora Paulista Universitária.

16. Skidmore T. (1989). O Preto no Branco: Raça e Nacionalidade no pensamento brasileiro. Rio de Janeiro: Editora Paz e Terra.

17. Skidmore T. (1994). O Brasil visto de fora. Rio de Janeiro: Editora Paz e Terra.

18. Skidmore T. (1998). Uma História do Brasil. Rio de Janeiro: Editora Paz e Terra, 2ed.

19. Schwarcz L. (1993). O espetáculo das raças. São Paulo: Companhia das Letras.

20. Marques V. (1997). Medicalização da raça. Campinas, Editora da Unicamp.

21. Peixoto A. (1938). Clima e Saúde. São Paulo: Companhia Editora Nacional.

22. Vianna O. (1959). Raça e Assimilação. Rio de Janeiro: José Olympio, 4 ed.

23. Couto M. (1932). Medicina e Cultura. Rio de Janeiro: Oscar Mano Cia, vol. 1.

24. Couto M. (1933). No Brasil só há um problema nacional: a educação do povo. Rio de Janeiro: Tipografia do Jornal do Comércio.

25. Penna B. (1923). Saneamento do Brasil. Rio de Janeiro: Editora Ribeiro dos Santos, 2 ed..

26. Hochman G. (1998). A era do saneamento: as bases da política de Saúde Pública no Brasil. São Paulo: Hucitec.

27. Hochman G, Lima N. (1998). Condenado pela raça, absolvido pela medicina: o Brasil descoberto pelo Movimento Sanitarista da Primeira república. In: Mato MC, Santos RV.
Raça, ciência e sociedade. Rio de Janeiro: Editora da Fundação Oswaldo Cruz, 23-40.

28. Azevedo F. (1933) O problema da regeneração. Rev. Educação Physica 5: 46.

29. Azevedo F. (1933). Op. cit, 14.

30. Pagni PA. (1994). Fernando de Azevedo: Educador do Corpo. São Paulo: Pontifícia Universidade Católica.

31. Pagni PA. (1994a). As representações sobre o moderno no projeto de educação do corpo desenvolvido por Fernando de Azevedo. In: Coletânea do II Encontro Nacional de História do Esporte, Lazer e Ed. Física. Ponta Grossa: Universidade Estadual de Ponta Grossa.

32. Azevedo F. (1934). Novos caminhos e novos fins. São Paulo: Melhoramentos.

33. Areno W. (1949). Higiene aplicada à Educação Física. Rio de Janeiro, s. c.p..

34. Areno W. (1941). Higiene e Saúde. Revista Educação Física 53: 32-33.

35. Busch R. (1943). Como evitar a prole doentia. Rev. Educação Física 71: 58.

36. A Eugenia e a Constituinte. (1933) Revista de Educação Física 2 (4): s.p. 